\title{
The Effect of Open Innovation Implementation on Small Firms' Propensity for Inbound and Outbound Open Innovation Practices
}

\author{
Naruetharadhol P' ${ }^{1}$, Srisathan W. A. ${ }^{1}$, Ketkaew C. ${ }^{11}$ \\ ${ }^{1}$ Department of Global Business, Khon Kaen University International College, 123 \\ Mitrphap Road, Muang, Khon Kaen, Thailand 40002
}

\begin{abstract}
Small- and medium-sized enterprises (SMEs) face limited resource capability to implement open innovation. Understanding a robust mechanism of knowledge management, organisational structure, and networks can benefit managerial and organisational drivers to achieve open innovation in general. The paper sheds the new light in developing the open innovation implementation as a latent endogenous variable influence inbound OI and outbound OI. We used structural equation modelling (SEM) on a data set of 636 Thai SMEs. The results reveal that open innovation implementation reflected by managerial and organisational dimensions has a positive impact on contributing to both inbound and outbound OI. A key finding is that open innovation's diffusion helps SMEs to overcome their technological capabilities to implement OI.
\end{abstract}

Keywords: Open innovation implementation; organisational structure; knowledge management; networks; inbound open innovation; outbound open innovation; structural equation modeling

\section{Introduction}

Recently, innovation has been growing to crucially reduce the time and cost related to product development to increase efficiency, leading to the practical use of a collaborative business design model in any industry [1]. As a result, open innovation (OI) is the ultimate solution to customer needs and market conditions [2]. Although SMEs seek external collaborators out innovative solutions through implementing crowdsourcing innovation [3], there is the number of issues unclear in managerial and organisational aspects to apply open innovation theory due to its broad concept. Thus, it is pivotal to specify the elements for opening up their innovation process. This research undertakes an evaluation of managerial and organisational drivers to develop into a new exogenous dimension of "open innovation implementation (OII)". In this context, this research poses two research questions: (1) how do the organisational and managerial dimensions (i.e., organisational structure, knowledge management, and

\footnotetext{
${ }^{1}$ Corresponding Author: Ketkaew C., Khon Kaen University International College, Thailand; E-mail: chaket@kku.ac.th
} 
networks) affect the implementation of open innovation? and (2) how OII contributes to inbound OI and outbound OI in practice? Prior studies have mostly paid attention to the effect of OI practices (e.g., inbound, outbound, and coupled [4], [5]) on innovation performance and firm performance. Yet, the effect of organisational and managerial dimensions on the implementation process is relatively constrained to investigate. The exploratory evidence reveals that organisational structure, knowledge management, and networks contribute to driving the firms' open innovation strategy [6]. Due to the indepth the large firm's experience in adopting the open innovation, the case study's results do not demonstrate the empirical support. This current research aims to propose the new exogenous dimension of "open innovation implementation as motivated by Thailand's knowledge economy and industrial sustainability. The second objective is to investigate the contribution of OII to open innovation practices empirically. We follow the scope of "implementation by Huizingh [7] that the process by which the firms open up their innovation process. More recently, Thailand is moving towards Thailand 4.0, which is driving the economy through innovation, focusing on science, technology and innovation to drive the economy. Also, Thailand has invested in research and development, only $0.2 \%$ of GDP [8]. Hence, Thailand serves as the field to investigate open innovation for the current study. Our key finding contributes to building a positive environment that stimulates people to leverage and develop the existing technological capabilities across the firm's boundaries. In addition, firms benefit from the outsourcing of knowledge so as to enhance recent technological development. Our results contribute to the insight into open innovation approach derive in small firms to use a unique data set collected from mainly CEOs, entrepreneurs, business owners, and managers across 636 SMEs. In particular, we find that managerial and organisational factors such as organisational structure, knowledge management and networks magnify the effect of open innovation implementation on inbound and outbound open innovation significantly. Understanding this effect would allow practitioners and policymakers to implement the motives of open innovation. The remaining sections of the paper are outlined as follows. Section 2 reviews the theoretical background literature and develop our conceptual framework and hypotheses forwards. Section 3 sets out the empirical application with Structural Equation Modeling (SEM) by which allows us to test OII as a latent endogenous variable. Section 4 discusses the main findings of the survey, along with the factor analysis and the latent regression analysis, and followed by Section 5 concludes and implies in practice.

\section{Theoretical Background}

\subsection{Theory of open innovation: Open innovation implementation (OII)}

This current study traces back academic support in the theory of open innovation [9]. We attempt to understand the implementation process. Inside the adoption stage, Rogers [10] indicate that the implementation stage involves the ways firms put an act of innovation into use based on the situation. While Huizingh [7] explains the implementation stage as the transitioning process from closed innovation towards open innovation. Chesbrough [9] defines open innovation as the process by which firms apply outside ideas as well as inside ideas, and inside and outside paths to market, as the firms seek to advance their technology. Boscherini, Chiaroni, Chiesa, \& Frattini [11] highlighted the implementation process toward open innovation which often starts 
with searching and outsourcing technological service firms. To transform from closed innovation to open innovation, managerial, organisational, and contextual dimensions (e.g. knowledge management, organisational structure, and networks respectively) are prerequisite to organise this change [6]. Beyond opening up the innovation process, the main managerial change has taken place in the managerial systems of firms. Lichtenthaler [5] suggested the OI paradigm can be opened up in a two-directional innovation process such as external technology acquisition (inbound OI) and internal technology exploitation (outbound OI). As prior studies (e.g., Boscherini et al. [11]; and Chiaroni et al. [6]) addressed, the implementation of open innovation reflects three main variables (knowledge management, organisational structure, and networks). These variables should be considered and taken action by the innovative firm to run an opening up as the process under the open innovation paradigm. Our research takes all three subconstructs of open innovation implementation into account and explores, whether they explain an valid dimensionality of the latter is needed.

\subsection{Knowledge management}

Knowledge management can be defined as the capability of organising or employing the information in a means by which it contributes to reaching set goals [12]. Singh, Gupta, Busso, \& Kamboj [13] indicate that knowledge management affects open innovation; for a reason, that open innovation implementation specifies the adoption of knowledge management. Knowledge management enables people to diffuse, share and transfer knowledge [6] as well as create, utilise, and store it within internal and external context. Mahmoudsalehi, Moradkhannejad, \& Safari [14] point out that knowledge management comprehensively includes the efforts activities of facilitating in acquiring and exploiting knowledge. While knowledge management is represented as an outcome of firm structure and strategy, it is essential to create, share, and utilise knowledge across the functional boundaries of firms [15]. Therefore, it is possible that knowledge management plays an essential role in explaining open innovation implementation and also affects organisational structure to support the mechanism of open innovation implementation. Our literature analysis linking knowledge management and organisational structure to open innovation implementation leads to the following hypotheses:

H1. Knowledge management positively influences open innovation implementation

H2. Organisational structure positively mediates the influence of knowledge management on open innovation implementation.

H3. Organisational structure

Organisational structure can be defined as how the organisation is connected for the most efficient operations, tasks, systems, operating processes, employees, and teams to accomplish business objectives [16]. Bai, Feng, Yue, \& Feng [17] argue that mechanical and organic organisation structure have an impact on innovation performance (e.g., new product development). Innovative product development requires multi-disciplinary knowledge for open innovation. Thus, the characteristics of the organisational structure have an impact on the operation of new goods advancement. Lee, Min, \& Lee [18] find that the decentralised structure in terms of decision-making affects outside-in and inside-out open innovation, indicating that 
decentralised workflow promotes discussion before the acceptance or rejection of recommendations from external collaborators.

H4. Organisational structure positively influences open innovation implementation

\subsection{Networks}

Networks can be defined as the scope of depth and breadth of inter-firm relationships that build during the project level with external actors. Such actors include universities, research institution, customers, government, and suppliers [19]. Perkmann \& Walsh [20] argue their finding that the network of inter-organisational relationships is needed to pay more attention, especially between universities and firms. This will help unlock the innovation problem once the openness comes at the door through the research area. To explain the features of a network for innovation, Laursen \& Salter [21] highlight two factors: breadth and depth. First, search depth is measured as the degree of the various search channels or external sources is drawn by firms. Second, search breadth is quantified as the number at which firms rely on their search channels or external sources. Taking all the above into account, we develop the following hypothesis:

H5. Networks positively influence open innovation implementation.

Taking all hypothesis 1,2 and 4 into account, we attempt to measure these latent constructs with the second-order model, whereas the arrows are reversed to reflect that organisational structure, knowledge management, and networks are the subdimensional influence explaining open innovation implementation. Thus, when the process of OI implementation is set up, and the next process will be explored the manners which how small firms practice whether their inbound or outbound activities.

\subsection{Open Innovation Practices: Inbound and Outbound}

During the implementation phase, firms plan to either externally acquire, internally exploit, or combine technological knowledge for innovation development [6]. Given its importance, a firm's strategies on technology play a key role in opening up the innovation process. In addition to acquiring external knowledge, firms can actively commercialise technology; for example, by means of out-licensing. The rise of inside and outside technology transactions reflects the new open innovation paradigm [22]. Wang, Chang, \& Shen [23] also explore the impact of inbound open innovation strategy on firm performance; their result suggests that external resources relying on horizontal and vertical technology collaboration are significant to the high-tech industry. Yoon, Shin, \& Lee [24] find that outbound open innovation usage, including outward technology transfer, venture business, joint venturing, and open platform, is most relevant to the active technology exploitation. We can conclude firms open up and establish networks with external firms access their competencies to improve firm innovation performance, referring to the process of how to do open innovation. Thus, this stage is related to the implementation stage. To summarise, our analysis linking the essence of managerial and organisational factors to inbound and outbound practices, and the practice stage tends to unfold an open innovation perspective onto existing processes. 
H6. Open innovation implementation as a second-order factor positively influences inbound open innovation in practice

H7. Open innovation implementation as a second-order factor positively influences outbound open innovation in practice

\section{Research methodology}

\subsection{Data collection and sampling}

From a whole population list of 699,382 firms, we elicited registered SMEs from DBD Data Warehouse. We collected data using a postal and electronic-mail survey questionnaire of a sample of 636 Thai SMEs. As suggested by Kline [25], the sample size acceptable for structural equation modelling was 10 observations per indicator variable. The 636 samples were designed based on the two-stage sampling approach. The cluster sampling is the first stage units to be sampled depending on the geographical region of Thailand and divided into 6 clusters, namely the North, Northeast, Central, East, and South. As firms sorted by geographic area, we apply purposive random sampling in the second stage, which allows us to access a purposeful category of small firms as our target. In this current research, small and medium enterprises (SMEs) are defined as the firms with no more than 250 employees, operating the production, distribution and service activities. SMEs are one of the focal points to drive Thailand's economic vitality and economic development [3], creating the number of employment for more than 10.5 million Thais. In Thailand, SMEs are considered as a beneficial source of innovation, new products into the market and aggregate productivity growth [26]. It can be concluded that Thai SMEs serve as the locale to examine the effect mechanism of open innovation implementation on inbound OI and outbound OI of SMEs.

\subsection{Measures and variable settings}

The constructs of the study were used measuring a 7-point Likert-type scale [27] ranging from 1 (strongly disagree) to 7 (strongly agree) and from 1 (strongly not important) to 7 (strongly important). In our research, open innovation implementation (OII) was estimated as the exogenous latent model caused by latent endogenous variables of knowledge management, organisational structure, and networks. On the other word, the first-order constructs of knowledge management, organisational structure, and networks will be used as indicators forming to measure open innovation implementation (OII). The measures were adopted with the major and minor change from the literature. Knowledge management was adapted from [15] measuring three items; how firms manage knowledge to create, share, and utilise innovation. The organisational structure was operationalised using five items from [15], [17] to measure activities that are designed to capture decentralisation (i.e., maintain open communications channels in operations), organism (i.e., encourage team collaboration and capability improvement to handle change), and mechanism (i.e., have both formal and informal procedures). Networks were adapted eight items from previous research to measure the scope of depth and breadth of external partners [19], [21] in terms of collaborations with industrial enterprises, university or other academic institutions, and public or government institutions. Inbound OI and outbound OI were adapted from [5], 
[23]. Inbound activities are designed to observe the technological and knowledge acquisition from external firms, the search for new trends and knowledge, and the ties with and reliance on external usage of innovation technology. While activities - the selling of technological knowledge and intellectual property, non-co-exploitive technology, and the establishment of a dedicated unit — are used to capture outbound open innovation.

\subsection{Descritive statistics}

Figure 1 exhibits that $32 \%$ of firms had an operational age of 0 to 10 years, businesses that had operated between 11 to 20 years made up (24.8\%) and those above 40 years comprised (20.8\%). The remaining firm's age comprised 21 to 30 years and 31 to 40 years has the followed distributions of $13.5 \%$ and $8.9 \%$ respectively. The result was found that $83.2 \%$ of respondents who are CEOs, Entrepreneurs, Business owners, managers, or other top executive positions. The other $16.8 \%$ of respondents were in lower positions. For the firm's location, almost half $(45.2 \%)$ of the firms are located in the Northeast region, followed by the Central Region (32.7\%). The other four regions are; are the East Region (7.3\%), the North Region (5.9\%), the South Region (5.6\%), and the West Region (3.3\%). Finally, we asked to ensure small firms' OI adoption, and the results showed that up to $90.6 \%$ of SMEs had adopted OI, and the rest $(9.4 \%)$ of firms having not adoption yet.

\section{Reliability and validity analysis}

The analysis was conducted in several steps. First, unidimensionality was conducted through exploratory factor analysis (EFA) using varimax rotation. The EFA results explained $61.34 \%$ of the total variance, indicating that all the measurement scales are well loaded on their constructs. Second, the analyses of Cronbach's alpha and composite reliability are greater than 0.70 , demonstrating the constructs are reliable [28], [29]. Third, the assessment of the construct validity is composed of convergent and discriminant validity to measure the conceptual variables. Using confirmatory factor analysis (CFA), the standardised factors loadings (see Table 1) obtained with a value of more than 0.70 [30]. The results of composite reliability (CR) exceed 0.70 , which means that the variables did converge at some point [30]. The values of average variable extracted (AVE) are over 0.50 , indicating the effective measure of the single latent construct [30]. This step 3 of convergent validity shows that there are the convergences on the latent variables to measure the same thing. Fourth, to test the discriminant validity of the measurement model, the results of the maximum shared variance (MSV) and the average squared variance (ASV) are less than the values of average variable extracted (AVE), meaning there are the divergences from other variables to measure different constructs. Fifth, the measurement model indices for open innovation implementation as a second-order factor explained: $x^{2}=251.722$ ( $\mathrm{p} \leq$ $0.001) ; \mathrm{CMIN} / \mathrm{df}=2.967 ; \mathrm{RMR}=0.042 ; \mathrm{GFI}=0.95 ; \mathrm{AGFI}=0.928 ; \mathrm{PGFI}=0.665$; $\mathrm{NFI}=955 ; \mathrm{RFI}=0.944 ; \mathrm{IFI}=0.97 ; \mathrm{CFI}=0.97 ; \mathrm{PNFI}=0.764 ; \mathrm{RMSEA}=0.056$. This indicates the good model fit [30]. To summarise, results confirm that open innovation implementation is represented as an overarching concept (i.e. second-order factor) consisting of knowledge management, organisational structure, and networks (firstorder factors). Sixth, the structural model was tested. The fit indices for the structural model were as follows: $x^{2}=244.709(\mathrm{p} \leq 0.001) ; \mathrm{CMIN} / \mathrm{df}=2.913$; $\mathrm{RMR}=0.041$; 
$\mathrm{GFI}=0.951 ; \mathrm{AGFI}=0.929 ; \mathrm{PGFI}=0.665 ; \mathrm{NFI}=0.956 ; \mathrm{RFI}=0.945 ; \mathrm{IFI}=0.971 ;$ $\mathrm{CFI}=0.971 ; \mathrm{PNFI}=0.765 ; \mathrm{RMSEA}=0.055$. All indices provide a good fit [30], revealing that the model fits the data well. The high standardised regression estimates further suggest that the proposed indicators support well the constructs being hypothesised to measure.

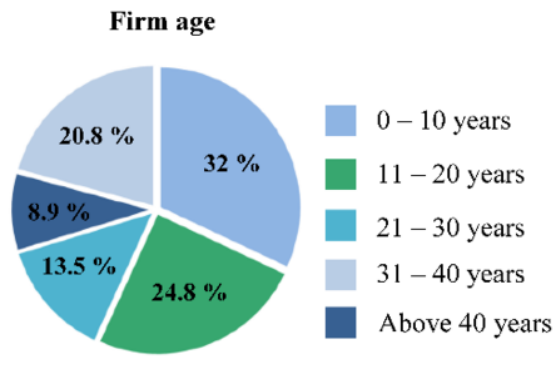

Geographical location

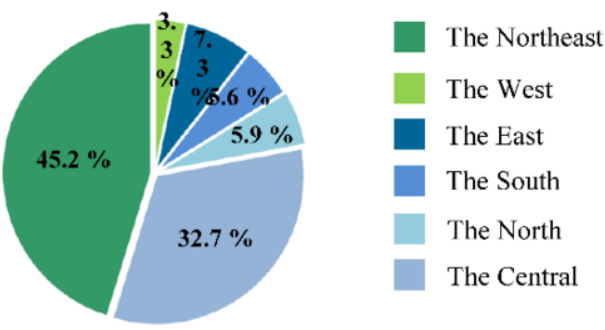

\section{Respondents' position}

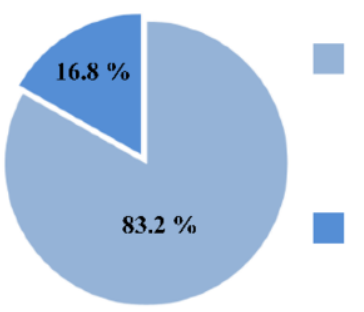

CEOs, Entrepreneurs, Business owners, managers, or other top executive positions

Lower than positions mentioned above
Does your firm adopt open innovation?

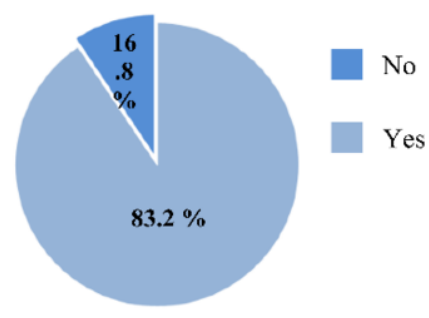

Figure 1. The characteristics of the sample and its distribution

Table 1. Discriminant validity, convergent validity, and reliability of measures.

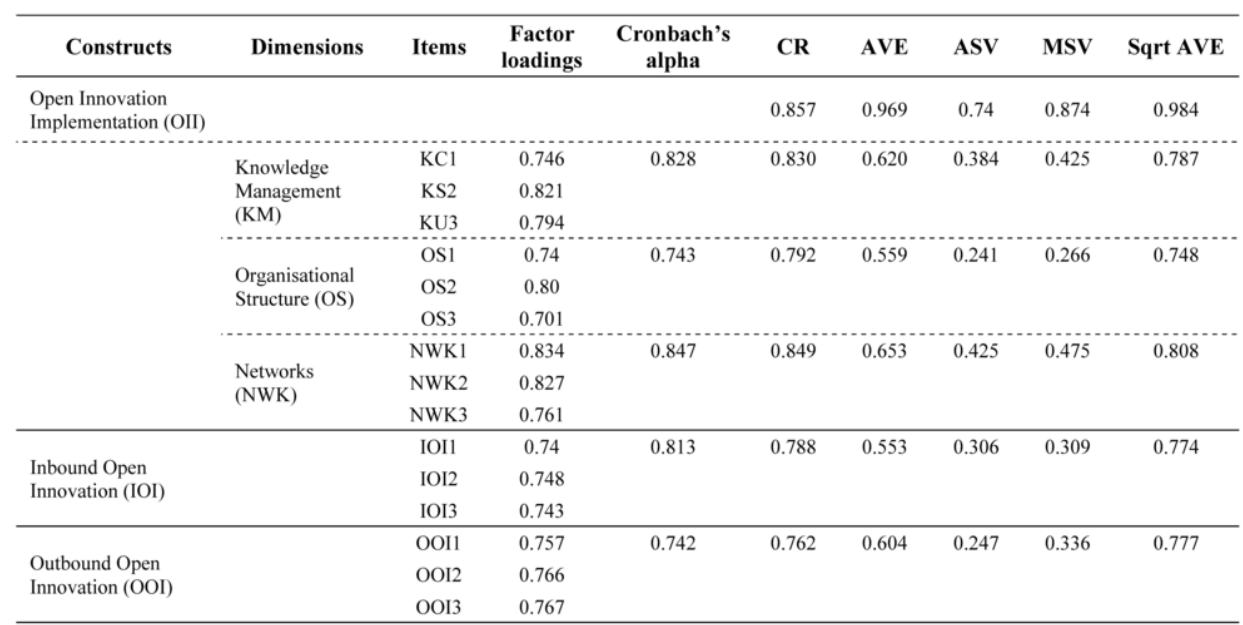




\section{Discussion and contributions}

This research attempts to test open innovation implementation as a second-order construct reflected by the first-order dimensions of knowledge management, organisational structure, and networks. We then investigate the influence of open innovation implementation (OII) on inbound and outbound practices. The coefficients and their standard estimates obtained structural equation modelling (SEM) in SPSS Amos v26, are in Figure 2. Hypothesis 1 to test the influence of knowledge management on open innovation implementation was confirmed $(\beta=0.945 ; t$-value $=$ 19.874; $P<0.001)$. The findings indicate that knowledge management plays an important role in innovation - how firms create, share, and utilise knowledge across firm boundaries - and knowledge management as an enabler can help firms manage decision-making and procedure with external partners. Meanwhile, Hypothesis $2(\beta=$ $0.503 ; t$-value $=2.79 ; P<0.001)$ were confirmed to knowledge management influence open innovation implementation via the mediating role of organizational structure. We find that knowledge management systems can be integrated when organisational structure as the mediating variable is a critical antecedent which allows firms to have open communication to share ideas and impact cross-functional innovation implementation to across firm boundaries. Besides, this result suggests that small firms acquire knowledge from the inside and exploit external knowledge in order to create new knowledge to the Hypothesis $3(\beta=0.47 ; t$-value $=2.814 ; P<0.001)$ found support, indicating organisational structure as the key important aspects firms need to authorise decisions, rules, and procedures to collaborate with external parties appropriately. The finding of hypothesis 4 tests networks contribute to open innovation implementation is acceptable $(\beta=0.874 ; t$-value $=21.113 ; P<0.001)$. indicating a variety of knowledge and technology sources need to obtain innovation that can be searched from external partners, especially from university-industrial collaboration. Regarding the confirmation of open innovation implementation construct, its impact has significantly on inbound and outbound open innovation practices. Thus, hypotheses $5(\beta=0.98 ; t$-value $=20.606 ; P<0.001)$ and $6(\beta=0.995 ; t$-value $=21.552 ; P<0.001)$ were supported that outbound OI and inbound OI are contributed positively to the firm's open innovation implementation process. Open innovation can be implemented through the knowledge management system, organisational structure, and networks, which leads to open innovation practices (i.e., inbound OI and outbound OI). This lends support to the work of Lichtenthaler \& Ernst [22] that aggressiveness of technology highly influences the strategic approach of firms toward open innovation. The theoretical contribution of this paper is twofold. First, we incorporate organisational structure, knowledge management, and networks into the research model, and find that they have different impacts on open innovation implementation (OII). When SMEs implement open innovation field by being connected through organisational management and dialogue such as the structure of management, the managerial system of knowledge, and business networks [6]. Second, this study also contributes when the underlying mechanisms that describe the causal effect of open innovation implementation (OII) on open innovation practices (OIP) have been appropriately created on the prior conceptual study of Huizingh [7]. From this view, our paper, emphasising on CEOs', entrepreneurs', business owners', managers', or other top executive positions' open innovation implementation as a critical contributing factor to inbound OI and outbound OI, advances our understanding of open innovation practices from three managerial and organisational drivers. To the best our knowledge, 
this paper demonstrates a new first scale on open innovation implementation, which establishes on recent qualitative and conceptual research on open innovation implementation that shows multiple dimensional constructs of open innovation implementation. For practical implications, the importance of organisational structure helps planning and decision making activities to come up with a new product or process innovation to be distributed to other technical expertise under business collaboration networks. Meanwhile, the focus of knowledge management is pointed at knowledge created, shared, and utilised inside and outside the firm to develop and exploit innovation through personal conversations, teamwork, training, and social media. Therefore, one of the main determinants of the extent to which firms attempt to open up the innovation process is constituted in a technology-based strategy. In addition, a flexible and knowledge incentive workplace can support team collaboration and makes it simple for them over their call of duty. All these implementation mechanisms can positively impact the outbound and inbound open innovation efforts of small firms. As a whole, these results of our study provide some policy initiatives and guides: (1) SMEs need a new venture fund from networks (e.g., university, public institutions, and industry); (2) compete for the market with co-creation and development; and (3) promote the cross-functional team in order to share knowledge across firm boundaries.

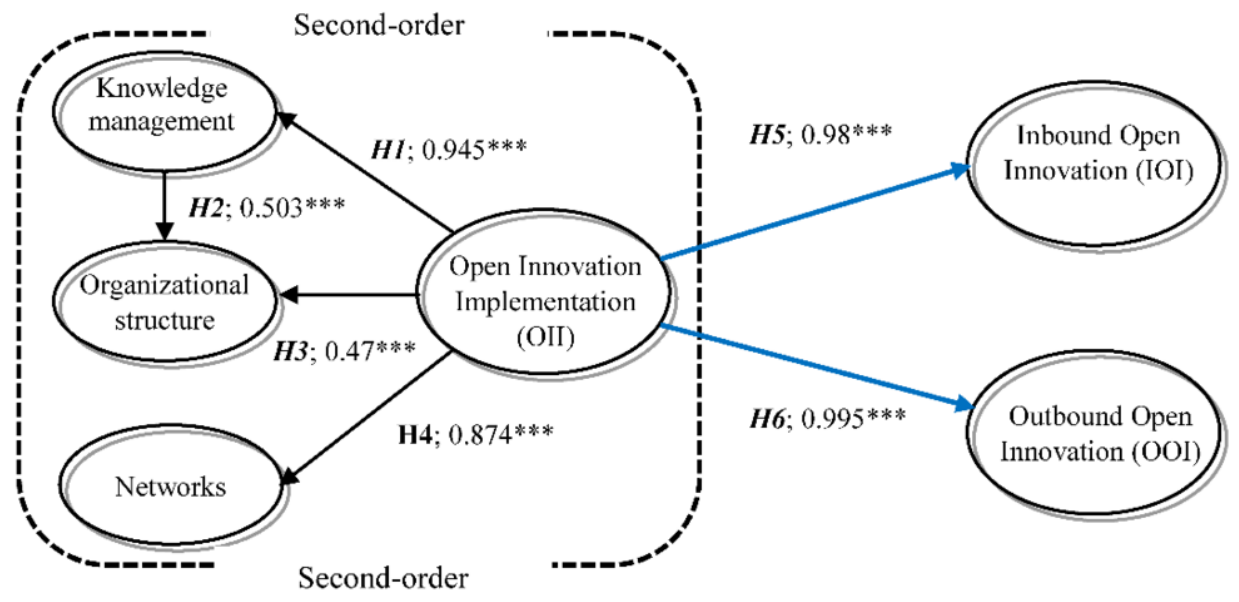

Figure 2. Structural model

\section{Conclusion, limitation, and future research}

By considering open innovation implementation as a three-dimensional construct and investigating its relationships with inbound and outbound open innovation practices in a single model, this study offers new theoretical insights to small business practitioners and policymakers. The open innovation implementation as a second-order model provides a significant insight into organisational structure, knowledge management, and networks. We reach the two research objectives by confirming that three managerial and organisational dimensions can be represented as the elements of open innovation implementation. The results prominently demonstrate there is a positive effect of open innovation implementation on open innovation practices, which both 
stages are relevant significantly. SMEs are encouraged to analyse their internal capabilities to adopt open innovation and evaluate the external dynamics to come up with new technology to the market. Eventually, these three strategic management and organisational dimensions assist in pushing open innovation strategy and bringing firms to innovative solution through internal and external collaboration. This study is not without limitations. First, open innovation implementation may have limited relevance in the case of large firms. Further investigation is encouraged to collect both large and small firms to compare the differences in their application. Motivated by [21], networks variable should be more validated through the measurement in the breadth and depth matrix to obtain the accurate number of external partners.

\section{References}

[1] Y. J. Chen, 'Knowledge integration and sharing for collaborative molding product design and process development', Comput. Ind., vol. 61, no. 7, pp. 659-675, Sep. 2010.

[2] M. R. Guertler, I. Michailidou, and U. Lindemann, 'How to assess a company's open innovation situation?', Des. Sci., vol. 2, 2016.

[3] W. A. Srisathan, C. Ketkaew, and P. Naruetharadhol, 'The intervention of organizational sustainability in the effect of organizational culture on open innovation performance: A case of thai and chinese SMEs', Cogent Bus. Manag., vol. 7, no. 1, Jan. 2020.

[4] M. M. Naqshbandi, S. K. Garib Singh, and P. Ma, 'The link between organisational citizenship behaviours and open innovation: A case of Malaysian high-tech sector', IIMB Manag. Rev., vol. 28, no. 4, pp. 200-211, Dec. 2016.

[5] U. Lichtenthaler, 'Outbound open innovation and its effect on firm performance: Examining environmental influences', $R$ D Manag., vol. 39, no. 4, pp. 317-330, Sep. 2009.

[6] D. Chiaroni, V. Chiesa, and F. Frattini, 'The Open Innovation Journey: How firms dynamically implement the emerging innovation management paradigm', Technovation, vol. 31, no. 1, pp. 34-43, Jan. 2011.

[7] E. K. R. E. Huizingh, 'Open innovation: State of the art and future perspectives', Technovation, vol. 31, no. 1, pp. 2-9, Jan. 2011.

[8] OSMEP, 'SME 4.0 The Next Economic Revolution', 2017.

[9] H. Chesbrough, Open innovation: The new imperative for creating and profiting from technology. Boston, Mass.: Harvard Business School Press., 2003.

[10] E. M. Rogers, Diffusion of Innovations, 5th ed. New York: Free Press, 2003.

[11] L. Boscherini, D. Chiaroni, V. Chiesa, and F. Frattini, 'How to use pilot projects to implement open innovation', Int. J. Innov. Manag., vol. 14, no. 6, pp. 1065-1097, Dec. 2010.

[12] R. V. D. Gonzalez and M. F. Martins, 'Knowledge management: An analysis from the organizational development', Journal of Technology Management and Innovation, vol. 9, no. 1. JOTMI Research Group, pp. 131-147, 2014.

[13] S. K. Singh, S. Gupta, D. Busso, and S. Kamboj, 'Top management knowledge value, knowledge sharing practices, open innovation and organizational performance', J. Bus. Res., 2019.

[14] M. Mahmoudsalehi, R. Moradkhannejad, and K. Safari, 'How knowledge management is affected by organizational structure', Learn. Organ., vol. 19, no. 6, pp. 518-528, Sep. 2012.

[15] C. Liao, S. H. Chuang, and P. L. To, 'How knowledge management mediates the relationship between environment and organizational structure', J. Bus. Res., vol. 64, no. 7, pp. 728-736, Jul. 2011.

[16] F. Damanpour and S. Gopalakrishnan, 'Theories of organizational structure and innovation adoption: The role of environmental change', J. Eng. Technol. Manag. - JET-M, vol. 15, no. 1, pp. 1-24, Mar. 1998.

[17] W. Bai, Y. Feng, Y. Yue, and L. Feng, 'Organizational Structure, Cross-functional Integration and Performance of New Product Development Team', in Procedia Engineering, 2017, vol. 174, pp. $621-629$.

[18] J. Lee, J. Min, and H. Lee, 'The Effect of Organizational Structure on Open Innovation: A Quadratic Equation', in Procedia Computer Science, 2016, vol. 91, pp. 492-501.

[19] J. Chen, Y. Chen, and W. Vanhaverbeke, 'The influence of scope, depth, and orientation of external technology sources on the innovative performance of Chinese firms', Technovation, vol. 31, no. 8, pp. 362-373, Aug. 2011. 
[20] M. Perkmann and K. Walsh, 'University-industry relationships and open innovation: Towards a research agenda', Int. J. Manag. Rev., vol. 9, no. 4, pp. 259-280, Dec. 2007.

[21] K. Laursen and A. Salter, 'Open for innovation: the role of openness in explaining innovation performance among U.K. manufacturing firms’, Strateg. Manag. J., vol. 27, no. 2, pp. 131-150, Feb. 2006.

[22] U. Lichtenthaler and H. Ernst, 'Opening up the innovation process: the role of technology aggressiveness', R\&D Manag., vol. 39, no. 1, pp. 38-54, Jan. 2009.

[23] C. H. Wang, C. H. Chang, and G. C. Shen, 'The effect of inbound open innovation on firm performance: Evidence from high-tech industry', Technol. Forecast. Soc. Change, vol. 99, pp. 222-230, Oct. 2015.

[24] B. Yoon, J. Shin, and S. Lee, 'Open Innovation Projects in SMEs as an Engine for Sustainable Growth', Sustainability, vol. 8, no. 2, p. 146, Feb. 2016.

[25] R. B. Kline, Principles and practice of structural equation modeling, Fourth Edition. Guilford Publications, 2015.

[26] M. Turner, S. Sermcheep, S. Anantasirijkiat, and P. Srisangnam, 'Small and medium-sized enterprises in Thailand: government policy and economic development', Asia Pacific J. Public Adm., vol. 38, no. 4, pp. 251-269, Oct. 2016.

[27] R. Likert, 'A technique for the measurement of attitudes', Arch. Psychol., vol. 140, 1932.

[28] C. Fornell and D. F. Larcker, 'Evaluating Structural Equation Models with Unobservable Variables and Measurement Error', J. Mark. Res., vol. 18, no. 1, pp. 39-50, Feb. 1981.

[29] M. Tavakol and R. Dennick, 'Making sense of Cronbach's alpha', International journal of medical education, vol. 2. IJME, pp. 53-55, 27-Jun-2011.

[30] J. F. Hair, W. C. Black, B. J. Babin, and R. E. Anderson, Multivariate Data Analysis, 7th edition. Upper saddle River, New Jersey, 2010: Pearson Education Limited, 2010. 